\title{
Severidade do míldio da cebola em sistema superadensado para as condições do Alto Vale do Itajaí - SC
}

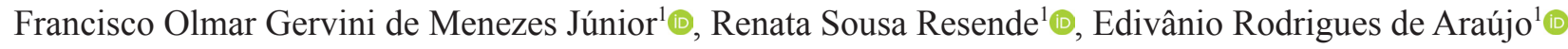

${ }^{1}$ Epagri, Estação Experimental de Ituporanga, Estrada Lageado Águas Negras, 453, C. Postal 121, CEP: 88400-000 - Ituporanga-SC, Brasil. Autor para correspondência: Francisco Olmar Gervini de Menezes Júnior (franciscomenezes@epagri.sc.gov.br) Data de chegada: 21/09/2020. Aceito para publicação em: 26/03/2021.

$10.1590 / 0100-5405 / 243824$

\section{RESUMO}

Menezes Júnior, F.O.G.; Resende, R.S.; Araújo, E.R. Severidade do míldio da cebola em sistema superadensado para as condições do Alto Vale do Itajaí - SC. Summa Phytopathologica, v.47, n.2, p.116-121, 2021.

O míldio é uma doença com alto potencial destrutivo para as lavouras de cebola. Os produtores de cebola têm adensado seus plantios com o objetivo de aumentar a produtividade, o que pode propiciar condições ainda mais favoráveis à doença. O objetivo do trabalho foi estudar o efeito da adubação nitrogenada e da população de plantas na severidade do míldio e produção de biomassa de bulbos sob cultivo superadensado para as condições do Alto Vale do Itajaí
- SC. Os tratamentos foram quatro populações de plantas $(400,600,800$ mil e 1,0 milhão de plantas ha $\left.^{-1}\right)$ submetidas a duas doses de nitrogênio (150 e $200 \mathrm{~kg} \mathrm{~N} \mathrm{ha}^{-1}$ ). Doses de nitrogênio, de 150 e $200 \mathrm{~kg} \mathrm{~N} \mathrm{ha}^{-1}$, não influenciam a severidade do míldio e a biomassa de bulbos. O aumento populacional de plantas a partir de 600 mil plantas por ha ${ }^{-1}$ aumenta a severidade do míldio e reduz a biomassa de bulbos.

Palavras-chave: Allium cepa, Peronospora destructor, nitrogênio, população de plantas, biomassa.

\section{ABSTRACT}

Menezes Júnior, F.O.G.; Resende, R.S.; Araújo, E.R. Severity of downy mildew on onions under super-dense system for the conditions at Alto Vale do Itajaí - Santa Catarina State, Brazil. Summa Phytopathologica, v.47, n.2, p.116-121, 2021.

Downy mildew is a disease with high destructive potential for onion crops. Onion producers have increased the density of their crops with the aim of rising productivity, which can provide even more favorable conditions for the disease. The aim of this study was to investigate the effect of nitrogen fertilization and plant density on the severity of downy mildew and bulb biomass production under super-dense cultivation for the conditions at Alto Vale do Itajaí - Santa
Catarina State, Brazil. Treatments consisted of four plant densities $(400,600$, 800 thousand and 1.0 million plants $\left.\mathrm{ha}^{-1}\right)$ receiving two nitrogen levels (150 and $200 \mathrm{~kg} \mathrm{~N} \mathrm{ha}^{-1}$ ). Nitrogen levels of 150 and $200 \mathrm{~kg} \mathrm{ha}^{-1}$ do not influence the severity of downy mildew and the biomass of bulbs. The increase in plant density from 600 thousand plants ha ${ }^{-1}$ increases the severity of downy mildew and reduces the biomass of bulbs.

Keywords: Allium cepa, Peronospora destructor, nitrogen, plant density, biomass.

O míldio (causado por Peronospora destructor (Berk.) Casp.), constitui-se numa das principais doenças da cultura da cebola na região do Alto Vale do Itajaí - SC, o que se deve à coincidência de condições favoráveis à doença (temperaturas amenas - em torno de $20^{\circ} \mathrm{C}$ e alta umidade - acima de 90\%) ocorrentes no período de cultivo $(16,17)$. É uma doença com alto potencial destrutivo que pode reduzir em até $75 \%$ a produtividade da cebola (5). Além das condições climáticas favoráveis, as epidemias do míldio tendem a ser favorecidas pelo aumento da população de plantas e adubação excessiva com fertilizantes minerais solúveis, em especial, do nitrogênio $(6,10,27)$.

No Alto Vale do Itajaí - SC (AVI), bem como no restante do Brasil, existe a tendência do adensamento das lavouras com o objetivo de se aumentar a produtividade. Nesta região, por características de adaptação, têm sido utilizados cultivares desenvolvidos localmente, com populações que raramente ultrapassam 400 mil plantas por hectare, enquanto em outras regiões, como o Vale do Rio do Peixe é comum o uso de 500 mil plantas por hectare. Estudos relacionados à densidade ideal de cultivo para os cultivares locais têm sido desenvolvidos na Epagri - Estação Experimental de Ituporanga com o objetivo de verificar a possibilidade de maior adensamento das lavouras. Nestes, a população máxima testada para os cultivares foi de 600 mil plantas ha $^{-1}$, com respostas de severidade do míldio e produtividade dependentes das condições climáticas e sistema de produção utilizado $(15,18,19,22)$.
A população de plantas pode influenciar diretamente a incidência e disseminação de doenças. Em geral, ao se aumentar a população de plantas ocorrem mudanças no microclima, tais como menor velocidade do vento, maior sombreamento e umidade relativa no interior do dossel e, por consequência maiores períodos de molhamento foliar, o que, juntamente com a menor distância entre plantas favorece a disseminação de unidades infectivas do patógeno e o processo doença. Estudos realizados por Boff et al. (3), com o cultivar Crioula no AVI, revelaram maior intensidade de doenças foliares na cultura da cebola para o menor espaçamento utilizado (maior população de plantas) e que independentemente deste, a pulverização com fungicida reduziu a severidade média da doença.

Além disso, o maior adensamento de plantas tende a reduzir o tamanho e a biomassa fresca e seca dos bulbos $(13,18)$ um aspecto indesejável ao se considerar que bulbos comerciais menores, produzidos em sistemas convencionais e racionais, com até $50 \mathrm{~mm}$ de diâmetro transversal (DT) e biomassa fresca (BF) abaixo de $70 \mathrm{~g}$, classificados na classe 2, recebem no mercado a metade do valor em relação a bulbos com maior DT e BF das classes superiores.

Considerando estes aspectos, o presente trabalho teve por objetivo estudar o efeito da adubação nitrogenada e da população de plantas na severidade do míldio e produção de biomassa de bulbos para as condições do Alto Vale do Itajaí-SC. 


\section{MATERIAL E MÉTODOS}

O experimento foi realizado no período de três safras (2017 a 2019), na Epagri/ Estação Experimental de Ituporanga, localizada no município de Ituporanga-SC $\left(27^{\circ} 38^{\prime} \mathrm{S}, 49^{\circ} 60^{\prime} \mathrm{O}\right.$, altitude de 475 metros). Segundo a classificação de Köeppen, o clima local é do tipo Cfa. O cultivar utilizado foi Empasc 352 Bola Precoce. O solo da área experimental é classificado como Cambissolo Háplico de textura argilosa.

A análise química do solo da área experimental apresentou para amostras retiradas na profundidade de $0-20 \mathrm{~cm}$, para os anos de 2017 , 2018 e 2019: $\operatorname{argila}=600 ; 450 ; 487 \mathrm{~g} \mathrm{~kg}^{-1} ; \mathrm{pH}\left(\mathrm{H}_{2} \mathrm{O}\right)=6,0 ; 6,0 ; 6,3$; $\mathrm{pH}\left(\right.$ índice SMP) $=6,4 ; 6,2 ; 6,3 ;$ M.O. $=40,0 ; 31,0 ; 23,8 \mathrm{~g} \mathrm{~kg}^{-1} ; \mathrm{P}$ (Mehlich-1) $=26,4 ; 13,1 ; 25,08 \mathrm{mg} \mathrm{dm}^{-3} ; \mathrm{K}=178,0 ; 109,0 ; 164,7 \mathrm{mg}$ $\mathrm{dm}^{-3} ; \mathrm{Ca}=8,1 ; 8,4 ; 12,35 \mathrm{cmolc} \mathrm{dm}^{-3} ; \mathrm{Mg}=2,7 ; 3,1 ; 5,3 \mathrm{cmolc} \mathrm{dm}^{-3} ; \mathrm{S}$ $=12,0 ; 36,0 ; 20,0 \mathrm{mg} \mathrm{kg}^{-1} ; \mathrm{CTC}(\mathrm{pH} 7,0)=14,06 ; 15,63 ; 21,20 \mathrm{cmolc}$ $\mathrm{dm}^{-3} ; \mathrm{Al}=0,0 ; 0,0 ; 0,0 \mathrm{cmolc} \mathrm{dm}^{-3} ; \mathrm{H}+\mathrm{Al}=2,8 ; 3,7 ; 3,1 \mathrm{cmolc} \mathrm{dm}^{-3}$, $\mathrm{Cu}=8,2 ; 4,4 ; 4,9 \mathrm{mg} \mathrm{dm}^{-3} ; \mathrm{Zn}=8,1 ; 5,1 ; 3,5 \mathrm{mg} \mathrm{dm}^{-3} ; \mathrm{Fe}=93 ; 95,5$; $64,5 \mathrm{mg} \mathrm{dm}^{-3} ; \mathrm{Mn}=37,0 ; 46,8 ; 14,2 \mathrm{mg} \mathrm{dm}^{-3} ; \mathrm{B}=2,4 ; 0,3 ; 0,2 \mathrm{mg} \mathrm{dm}^{-3}$.

Mudas do cultivar Empasc 352 Bola Precoce foram produzidas com base nos referenciais tecnológicos propostos pelo Sistema de Produção para a Cebola (7) e Manual de Boas Práticas Agrícolas (20). As semeaduras foram realizadas em 20/04/2017, 18/04/2018 e 23/04/2019, os transplantes em 20/07/2017, 18/07/2018 e 17/07/2019 e as colheitas em 14/11/2017, 13/11/18 e 07/11/2019. As áreas experimentais foram semeadas com milheto ( $30 \mathrm{~kg}$ sementes ha ${ }^{-1}$ ) no final de dezembro do ano anterior de cada ano de plantio. Antes do plantio das mudas de cebola as plantas de cobertura foram dessecadas com herbicidas, sendo realizado o preparo convencional do solo com arado e grade, e no solo das áreas experimentais foi aplicado em cada ano, em pulverização, 10 $\mathrm{kg}$ de ácido bórico ha ${ }^{-1}$ e $20 \mathrm{~kg}$ de sulfato de zinco ha-1.

Os tratamentos consistiram de quatro populações de plantas (400, 600,800 mil e 1,0 milhão de plantas $\mathrm{ha}^{-1}$ ) submetidas a duas doses de nitrogênio (150 e $200 \mathrm{~kg} \mathrm{~N} \mathrm{ha}^{-1}$ ).

As populações de plantas de 400, 600, 800 mil e 1,0 milhão de plantas ha ${ }^{-1}$ foram estabelecidas com os espaçamentos de $20 \mathrm{~cm}$ entre linhas e de 12,5, 8,3, 6,3 e 5,0 cm entre plantas, respectivamente.

As adubações de base com fósforo (superfosfato simples) e potássio (cloreto de potássio) foram realizadas considerando a análise de solo e recomendações da CQFS-RS/SC (4) para expectativa de produtividades de $50 \mathrm{t} \mathrm{ha}^{-1}$. Isso foi feito ao considerar a expectativa de rendimento da lavoura $\left(40 \mathrm{t} \mathrm{ha}^{-1}\right)$ e o número maior de plantas por hectare adotado no experimento (10 t ha ${ }^{-1}$ ). Assim, em 2017, 2018 e 2019 foram aplicados o equivalente a 140,220 e $160 \mathrm{~kg} \mathrm{P}_{2} \mathrm{O}_{5} \mathrm{ha}^{-1}$ e 150,165 e $150 \mathrm{~kg} \mathrm{~K} \mathrm{O}$ $\mathrm{ha}^{-1}$. Por sua vez as doses de nitrogênio (nitrato de amônio) foram parceladas $15 \%$ base, $25 \%$ aos 30 DAT e 50 DAT, $30 \%$ aos 70 DAT e $5 \%$ aos 90 DAT.

Para o manejo do míldio, foram realizadas pulverizações semanais de fungicidas registrados para a cultura, nas respectivas doses recomendadas pelo fabricante. Em 2017, utilizaram-se fungicidas que continham os seguintes princípios ativos: metalaxil-m + mancozebe, metalaxil-m + clorotalonil, mancozebe e oxicloreto de cobre. Em 2018 e 2019, além dos princípios ativos citados, utilizaram-se fungicidas que continham: propinebe, cloridrato de propamocarbe + fluopicolida, e cimoxanil + famoxadona.

O delineamento experimental utilizado foi de blocos ao acaso, em esquema fatorial (4 populações de plantas x 2 doses de nitrogênio), com quatro repetições. A área total de cada parcela experimental foi de 9,6 $\mathrm{m}^{2}$ (3,0 x 3,2 $\mathrm{m}$ com área útil 7,8 $\left.\mathrm{m}^{2}\right)$.

A severidade do míldio foi mensurada semanalmente em 2017 (16 avaliações) e quinzenalmente em 2018 e 2019 (8 avaliações em cada ano), utilizando uma escala descritiva proposta por Mohibullah (23), a qual estipula notas de área foliar lesionada para toda a parcela experimental. Os valores das notas de área foliar lesionada foram integralizados e calculados pela área abaixo da curva de progresso da doença - AACPD (26).

A biomassa fresca dos bulbos foi obtida a partir da amostragem e pesagem em balança digital de cinco bulbos representativos de cada parcela experimental, sendo utilizado o valor médio para a caracterização de cada repetição. Os cinco bulbos representativos de cada parcela experimental foram individualmente levados para estufa de ar forçado a $60^{\circ}$ até peso constante e, posteriormente, um por um, pesados para compor o valor médio representativo de cada repetição.

Durante os experimentos, registraram-se na Estação Meteorológica da Epagri/ EE de Ituporanga, para os anos de 2017, 2018 e 2019, as temperaturas médias, mínimas e máxima do ar, a umidade relativa média do ar e a precipitação, considerando os períodos do desenvolvimento inicial e desenvolvimento e maturação dos bulbos e as variações meteorológicas diárias - Tabela 1 e Figura 1 (8).

Tabela 1. Variáveis meteorológicas ocorrentes nos períodos de desenvolvimento da cebola nos anos agrícolas de 2017,2018 e 2019. Epagri, Ituporanga, SC.

\begin{tabular}{|c|c|c|c|c|c|c|c|c|c|}
\hline \multirow[t]{2}{*}{ Variáveis meteorológicas } & \multicolumn{3}{|c|}{ Desenvolvimento inicial } & \multicolumn{3}{|c|}{$\begin{array}{l}\text { Desenvolvimento e maturação dos } \\
\text { bulbos }\end{array}$} & & & \\
\hline & \multicolumn{3}{|c|}{ Julho a setembro } & \multicolumn{3}{|c|}{ Outubro a novembro } & \multicolumn{3}{|c|}{ Ciclo } \\
\hline $\mathrm{T}^{\mathrm{o}}$ média & 16,8 & 15,4 & 15,7 & 18,7 & 18,9 & 20,4 & 17,7 & 17,1 & 18,0 \\
\hline $\mathrm{T}^{\mathrm{o}}$ máx média & 23,3 & 21,2 & 21,5 & 24,9 & 23,7 & 26,2 & 24,1 & 22,4 & 23,9 \\
\hline \multirow[t]{2}{*}{ UR\% } & 80,9 & 86,8 & 83,5 & 78,5 & 89,4 & 80,6 & 79,7 & 88,1 & 82,1 \\
\hline & \multicolumn{3}{|c|}{ Julho a setembro } & \multicolumn{3}{|c|}{ Outubro a novembro } & \multicolumn{3}{|c|}{ Soma } \\
\hline
\end{tabular}



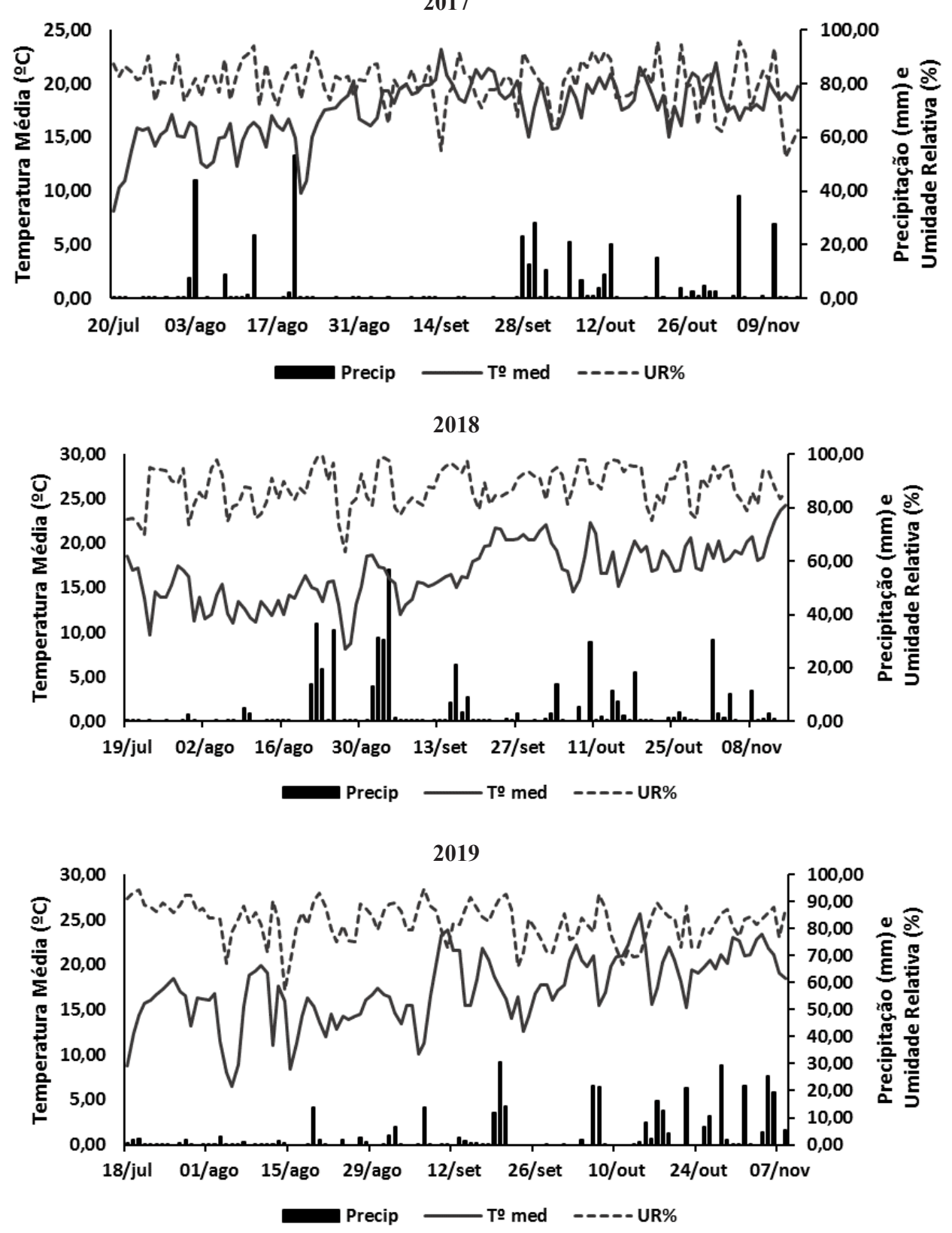

Figura 1. Variação diária da precipitação $(\mathrm{em} \mathrm{mm})$, da temperatura média $\left({ }^{\circ} \mathrm{C}\right)$ e da umidade relativa do ar $(\%)$ nos períodos experimentais (transplante a colheita) em 2017 (a), 2018 (b) e 2019 (c). Epagri, Ituporanga, SC.

Os dados experimentais foram submetidos à análise de variância, análise de regressão e teste de Tukey a $5 \%$ de probabilidade de erro com o programa estatístico " $\mathrm{R}$ " (25).

\section{RESULTADOS E DISCUSSÃO}

\section{Severidade do míldio (SM)}

Em relação a severidade do míldio, calculada pela $\mathrm{AACPD}$, não foram observadas interações significativas $(p>0,05)$ entre as doses de nitrogênio e as populações de plantas para nenhuma das safras avaliadas (Tabela 2).

As doses de nitrogênio aplicadas não influenciaram significativamente $(\mathrm{p}>0,05)$ a AACPD em nenhum dos anos agrícolas.
Portanto, o aumento da dose de nitrogênio de 150 para $200 \mathrm{~kg} \mathrm{ha}^{-1}$ não interferiu na AACPD. Resultados similares foram obtidos por Gonçalves et al. (10) e Gonçalves et al. (11), os quais para o mesmo tipo de solo (Cambissolo) não observaram a tendência de aumento da AACPD pela adição de adubação nitrogenada conforme sugerido por Huber (1991) e Huber e Arny (1985), citados por Huber (14).

Estudos realizados por Acharya \& Shrestha (1), revelaram que doses de nitrogênio abaixo (em 60 e 80\%) ou acima (em 140\%) das recomendadas podem promover o aumento da severidade do míldio em plantas de cebola. No presente experimento, mesmo em solo com teores médios do nutriente (M.O. $=40,0$ e $31,0 \mathrm{~g} \mathrm{~kg}^{-1}$ ) e sob o fornecimento de doses superiores em 50 e $100 \%$ da indicada para a cultura pela Comissão de Química e Fertilidade do Solo - RS/SC (4) não foi observada influência da adubação nitrogenada sobre a AACPD. 
Possivelmente, isso se deva ao modo de parcelamento do nitrogênio (distribuição das doses aplicadas ao longo do ciclo de cultivo) e a fonte do nutriente utilizada (nitrato de amônio). Nesse sentido, de acordo com Huber (1991) e Huber e Watson (1970), citados por Huber (14), o aumento da AACPD pela adição de adubos nitrogenados ocorre com o $\mathrm{N}$ na forma nítrica, que é prontamente disponível nos tecidos foliares, onde ocorre a infestação de parasitas obrigatórios, enquanto que o $\mathrm{N}$ na forma amoniacal é primariamente metabolizado nas raízes.

Por sua vez, a AACPD foi significativamente $(p<0,05)$ influenciada nos anos de 2018 e 2019 pela população de plantas.

Em 2017, a ausência de diferença na AACPD entre as populações de plantas possivelmente possa estar relacionada a menor umidade relativa do $\operatorname{ar}(79,7 \%)$ e maiores temperaturas máximas médias $\left(24,1^{\circ} \mathrm{C}\right)$ registradas durante o ciclo da cultura em relação aos demais anos agrícolas. A esporulação do míldio depende da alternância de períodos diurnos e noturnos, e a produção de esporângios ocorre somente à noite e em condições favoráveis (umidade relativa do ar acima de $93 \%$ e temperaturas entre 4 a $24^{\circ} \mathrm{C}$ ), enquanto temperaturas diurnas acima de $25^{\circ} \mathrm{C}$ podem inibir a esporulação na noite subsequente (6). Assim, sob umidades relativas do ar abaixo de $80 \%$ e temperaturas acima de $24^{\circ} \mathrm{C}$ ocorre a paralisação do desenvolvimento e não há esporulação de $P$. destructor (24). Apesar das condições menos favoráveis à ocorrência e severidade da doença, os valores de AACPD em 2017 foram maiores que em 2018 e 2019. Isto ocorreu possivelmente devido ao maior número de avaliações em 2017 (12 avaliações, realizadas semanalmente), enquanto em 2018 e 2019 foram realizadas cinco avaliações, quinzenalmente. A introdução de outros fungicidas nos tratamentos fitossanitários realizados em 2018 e 2019 pode explicar parcialmente os maiores valores de biomassa nestes anos, quando comparados a 2017. Propinebe, aplicado isoladamente, resultou em maiores valores de produtividade $(\approx 20 \%)$ que o tratamento com metalaxil-m + mancozebe, porém não diferiu estaticamente quanto à

\section{AACPD (2)}

Harms et al. (12), para duas safras agrícolas com o cultivar Bola Precoce na região de Ponta Grossa/PR, não observaram diferenças significativas para a severidade do míldio em relação a populações de 363 a 606 mil plantas ha ${ }^{-1}$. No presente trabalho, nos anos de 2018 e 2019, percebe-se a tendência do aumento da severidade com o aumento populacional a partir de 600 mil plantas ha-1 (Tabela 2). Estes foram anos com maiores umidades relativas do ar (médias anuais de $88,1 \mathrm{e}$ $82,1 \%$ ) que combinadas com o aumento da densidade populacional proporcionou, possivelmente, maior umidade/molhamento foliar.

\section{Biomassa fresca e seca de bulbos}

Não foram observadas interações significativas $(p>0,05)$ entre as doses de nitrogênio e as populações de plantas, para nenhuma das safras avaliadas, em relação a biomassa fresca (BF) e seca (BS) dos bulbos (Tabela 3).

As doses de nitrogênio aplicadas não influenciaram significativamente $(\mathrm{p}>0,05)$ a BF e BS em nenhum dos anos agrícolas. Resultados semelhantes foram observados por Acharya \& Shrestha (1), ao elevar em 20 e $40 \%$ a dose nitrogênio fornecida às plantas de cebola em relação a recomendação de referência. Por sua vez, estudos realizados nas condições edafoclimáticas do AVI indicam que a maior produção de bulbos com biomassa superior a $70 \mathrm{~g}$ (bulbos da classe 3) para populações de até 600 mil plantas ha-1 ${ }^{-1}$ em solos com teores de MO médios (32,0 e 33,0 $\mathrm{g} \mathrm{kg}^{-1}$ ), está associada a adubação nitrogenada

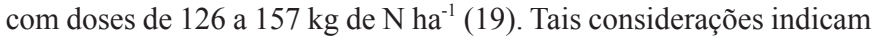
que a menor dose aplicada $\left(150 \mathrm{~kg} \mathrm{~N} \mathrm{ha}^{-1}\right)$ já seria, para os teores de matéria orgânica do solo (baixo em 2019 e médios em 2017 e 2018), suficiente para suprir o nutriente às plantas.

Por sua vez, as variáveis BF e BS dos bulbos foram influenciadas significativamente $(\mathrm{p}>0,05)$ pelo aumento da população de plantas (Tabela 3). Observou-se que, à exceção de BS em 2017, o aumento

Tabela 2. Área abaixo da curva de progresso da doença (AACPD) ocasionada pelo míldio da cebola (Peronospora destructor), em resposta a doses de nitrogênio (Dose de N) e população de plantas (População). Epagri, Ituporanga, SC.

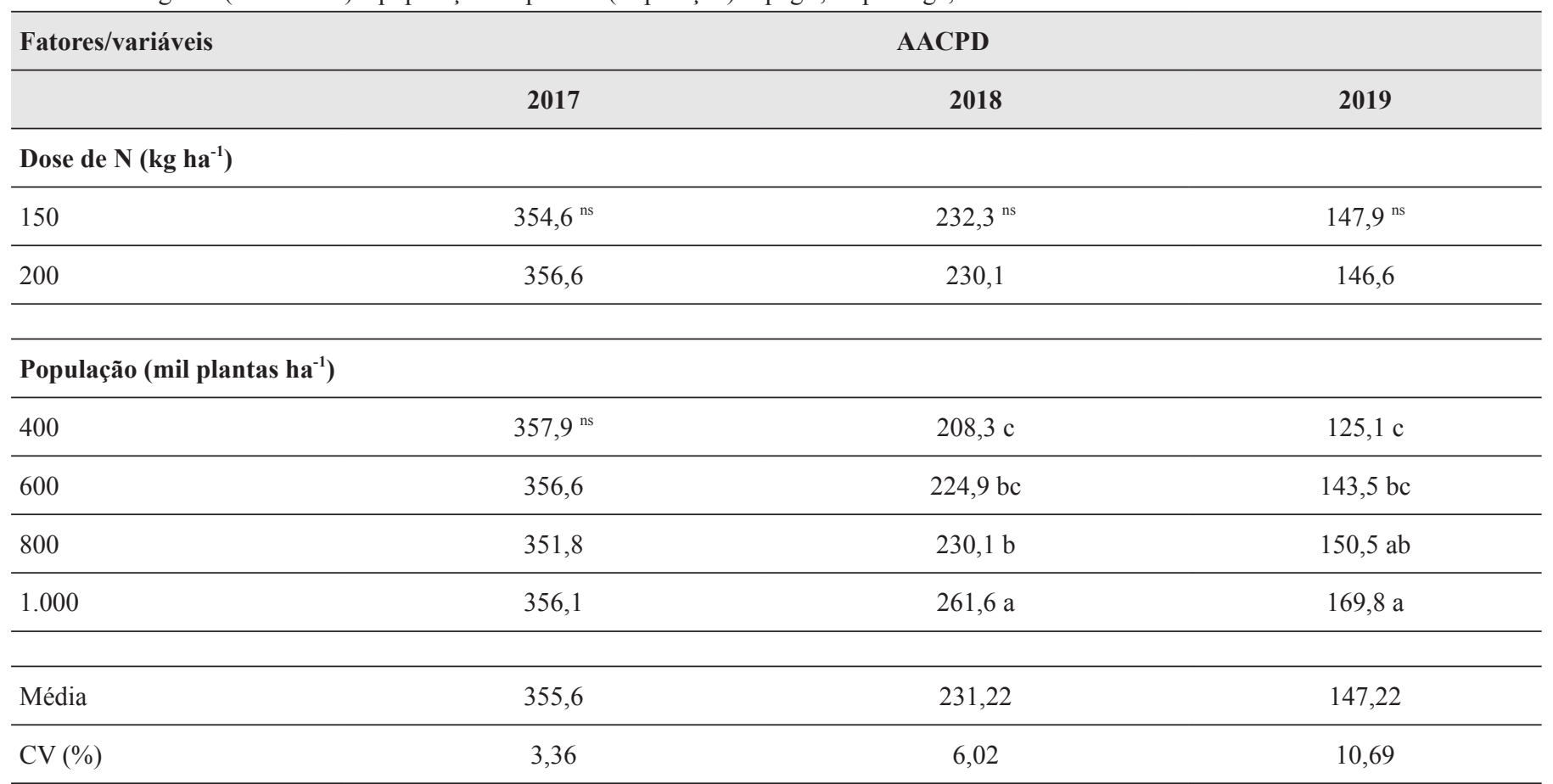

Médias seguidas pela mesma letra na coluna não diferem entre si, pelo teste de Tukey, a $5 \%$ de significância. ${ }^{\text {ns }}=$ não significativo. 
Tabela 3. Biomassa fresca (BF) e seca (BS), em gramas, dos bulbos para doses de nitrogênio (Dose de N) e população de plantas (População). Epagri, Ituporanga, SC.

\begin{tabular}{|c|c|c|c|c|c|c|}
\hline \multirow[t]{2}{*}{ Fatores/variáveis } & \multicolumn{3}{|c|}{ BF (gramas) } & \multicolumn{3}{|c|}{ BS (gramas) } \\
\hline & 2017 & 2018 & 2019 & 2017 & 2018 & 2019 \\
\hline 150 & $49,33^{\mathrm{ns}}$ & $65,11^{\text {ns }}$ & $74,38^{\mathrm{ns}}$ & $4,67^{\mathrm{ns}}$ & $6,86^{\mathrm{ns}}$ & $8,02^{\text {ns }}$ \\
\hline \multicolumn{7}{|c|}{ População (mil plantas ha' ${ }^{-1}$ ) } \\
\hline 400 & 57,96 a & $96,50 \mathrm{a}$ & $106,89 \mathrm{a}$ & $5,23^{\mathrm{ns}}$ & $9,29 \mathrm{a}$ & $10,99 \mathrm{a}$ \\
\hline 600 & $48,88 \mathrm{ab}$ & $63,89 \mathrm{~b}$ & $65,81 \mathrm{~b}$ & 4,68 & $6,59 \mathrm{~b}$ & $7,28 \mathrm{~b}$ \\
\hline Média & 50,66 & 66,85 & 75,13 & 4,79 & 6,92 & 8,08 \\
\hline $\mathrm{CV}(\%)$ & 13,55 & 20,89 & 8,47 & 13,99 & 17,97 & 8,75 \\
\hline
\end{tabular}

Médias seguidas pela mesma letra na coluna não diferem entre si, pelo teste de Tukey, a $5 \%$ de significância. ${ }^{\text {ns }}=$ não significativo.

populacional reduziu a BF e BS bulbos a partir de populações de 600 mil plantas $\mathrm{ha}^{-1}$.

Em 2017, a formação de bulbos com BF inferior a $70 \mathrm{~g}$ também pode estar relacionada às condições meteorológicas adversas de cultivo. Observa-se que neste ano agrícola houve precipitações irregulares e esparsas (de 21 de agosto a 27 de setembro a precipitação foi de apenas $5,2 \mathrm{~mm}$ ), o que combinado a temperaturas mais elevadas (máxima média do ar superior a $23,3^{\circ} \mathrm{C}$ ) e menor umidade relativa média do ar (80,9\%) em relação aos demais anos agrícolas, prejudicou o desenvolvimento inicial das plantas e, por consequência, a produção.

Observou-se também, considerando os dados experimentais por parcela para os anos agrícolas, que a BF e BS estiveram negativamente correlacionadas a severidade do míldio $\left(\mathrm{r}_{\mathrm{BF}}=-0,57 ; \mathrm{r}_{\mathrm{BS}}=-0,72\right)$ indicando que a severidade de míldio reduziu a biomassa dos bulbos.

A redução da BF e BS com o aumento da população está relacionada, além da severidade do míldio e outros fatores, a questões adaptativas dos cultivares utilizados. No Estado de Santa Catarina, devido ao clima úmido e frio, predomina o uso de cultivares de polinização aberta desenvolvidas e adaptadas localmente, a exemplo da Empasc 352 Bola Precoce, as quais têm-se mostrado pouco afeitos a um adensamento maior, comum em outras regiões brasileiras, como São Paulo, Minas Gerais e Goiás, onde é corriqueiro o uso de cultivares híbridas semeadas em densidades de 600 a 1,2 milhão de plantas ha-1 (21).

No estado de Santa Catarina, o uso de populações de 500.000 plantas ha ${ }^{-1}$ para cultivares de polinização aberta tem sido recomendado apenas para sistemas de produção diferenciados, como o fertirrigado, e são comuns em regiões com melhores condições edafoclimáticas, onde há um menor período de molhamento foliar, como a região do Vale do Rio do Peixe - SC $(9,19,21)$.

De acordo com os dados experimentais, verifica-se que as doses de nitrogênio, de 150 e $200 \mathrm{~kg} \mathrm{~N} \mathrm{ha}^{-1}$, não influenciam a severidade do míldio e a biomassa de bulbos em solo com teores baixo e médio de matéria orgânica, e que o aumento populacional de plantas a partir de 600 mil plantas por ha ${ }^{-1}$ aumenta a severidade do míldio em anos com condições favoráveis para o desenvolvimento da doença e reduz a biomassa de bulbos.

\section{REFERÊNCIAS}

1. Acharya, B.; Shrestha, R. Nitrogen Level and Irrigation Interval on Mitigating Stemphylium Blight and Downy Mildew in Onion. International Journal of Applied Sciences and Biotechnology, Lamjung, v.6, n.1, p.17-22, 2018.

2. Araújo E.R.; Resende, R.S. Propineb efficiency in controlling downy mildew of onion under field conditions. Australasian Plant Disease Notes, Melbourne, v.15, n.34, p.33-35, 2020.

3. Boff, P.; Stuker, H.; Gonçalves, P.A.S. Influência da densidade de plantas na ocorrência de doenças foliares e produção de bulbos de cebola. Fitopatologia Brasileira, Brasília, v.23, n.4, p.448-452, 1998.

4. Comissão de Química e Fertilidade do Solo RS/SC. Manual de adubação e de calagem para o Estado do Rio Grande do Sul e Santa Catarina. Santa Maria: SBCS/Núcleo Regional Sul, 2016. 376p.

5. Develash, R.K.; Sugha, S.K. Incidence of onion downy mildew and its impact on yield. Indian Phytopathology, Nova Delhi, v.50, n.1, p.127-129. 1997.

6. Domingues, R.J.; Töfoli, J.G. Míldio da cebola: importância, identificação e métodos de controle. Biológico, São Paulo, v.71, n.1, p.29-31, 2009.

7. Epagri. Sistema de produção para cebola: Santa Catarina. Epagri. Florianópolis: Epagri, 2013. 106p. (Sistemas de Produção, 46).

8. Epagri. Banco de dados de variáveis ambientais de Santa Catarina. Florianópolis: Epagri, 2020. 20p. (Epagri Documentos, 310).

9. Epagri. Avaliação de cultivares para o estado de Santa Catarina 20202021. Florianópolis: Epagri, 2020. 90p. (Epagri Boletim Técnico, 194).

10. Gonçalves, P.A.S.; Sousa e Silva, C.R.; Boff, P. Incidência do míldio em cebola sob adubação mineral e orgânica. Horticultura Brasileira, Brasília, DF, v.22, n.3, p.538-542, 2004.

11. Gonçalves, P.A.S.; Wordel Filho, J.A.; Kurtz, C. Efeitos da adubação sobre a incidência de tripes e míldio e na produtividade da cultura da cebola míldio e na produtividade da cultura da cebola. Agropecuária Catarinense, Florianópolis, v.22, n.1, p.57-60, 2009. 
12. Harms, M.G.; Dalla Pria, M.; Rezende, B.L.A.; Prestes, A.M.C; Dalazoana F. Influência da densidade de plantas e do uso de fungicida nas doenças foliares e na produtividade de cebola. Horticultura Brasileira, Brasília, v.33, n.2, p.203-207, 2015.

13. Henriques, G.P.S.A.; Grangeiro, L.C.; Paulino, R.C.; Marrocos, S.T.P.; Sousa, V.F.L.; Ribeiro, R.M.P. Produção de cebola cultivada sob diferentes densidades de plantio. Revista Brasileira de Engenharia Agrícola e Ambiental, Campina Grande, v.18, n.7, p.682-687, 2014.

14. Huber, D.M. The influence of mineral nutrition on vegetable diseases. Horticultura Brasileira, Brasília, DF, v.12, n.2, p.206-214, 1994.

15. Marcuzzo, L.L.; Menezes Junior, F.O.G; Gonçalves, P.A.S. Severity of onion downy mildew in different production systems. Summa Phytopathologica, Botucatu, v.42, n.4, p.366-368, 2016.

16. Marcuzzo, L.L.; Araújo, E.R. Manejo de doenças. In: Menezes Júnior, F.O.G.; Marcuzzo, L.L. (org.). Manual de práticas agrícolas: guia para a sustentabilidade das lavouras de cebola do estado de Santa Catarina. Florianópolis: Departamento Estadual de Marketing e Comunicação, 2016. v.1. cap.9, p.91-111.

17. Marcuzzo, L.L. Validação de um sistema de previsão para o míldio da cebola. Summa Phytopathologica, Botucatu, v.43, n.4, p.348-352, 2017.

18. Menezes Júnior F.O.G.; Vieira Neto J. Produção da cebola em função da densidade de plantas. Horticultura Brasileira, Brasília, v.30, n.4, p.733739, 2012.

19. Menezes Júnior, F.O.G.; Kurtz, C. Produtividade da cebola fertirrigada sob diferentes doses de nitrogênio e densidades populacionais. Horticultura Brasileira, Brasília, DF, v.34, n.4, p.571-579, 2016.
20. Menezes Júnior, F.O.G. Aspectos fitotécnicos. In: Menezes Júnior, F.O.G.; Marcuzzo, L.L. (org.). Manual de Boas Práticas Agrícolas: Guia para a sustentabilidade das lavouras de cebola do estado de Santa Catarina. Florianópolis: Epagri, 2016. v.1. cap.3 p.41-48.

21. Menezes Júnior, F.O.G.; Araújo, E.R. O estande ideal para a lavoura de cebola. Revista Campo \& Negócios Hortifrúti, Uberlândia, n.161, p.2427, 2018.

22. Menezes Júnior, F.O.G.; Gonçalves, P.A.S.; Marcuzzo, L.L. Avaliação de sistemas de produção convencional, racionais integrados e orgânicos na cultura da cebola em cultivo convencional e de plantio direto. Revista Thema, Pelotas, v.17, n.1, p.95-113, 2020.

23. Mohibullah, A. Studies on major diseases of bulb vegetables (onion and garlic) in NWFP. (Pakistan). Tarnab Peshawar: Agricultural Research Institute, 1992.

24. Pereira, R.B.; Oliveira, V.R.; Pinheiro, J.B. Diagnose e manejo de doenças fúngicas na cultura da cebola. Brasília, DF: Embrapa Hortaliças, 2014. 20p. (Circular Técnica, 133).

25. R Core Team. R: A language and environment for statistical computing. Vienna: R Foundation for Statistical Computing, 2017. Disponível em: $<$ https://www.R-project.org/>. Acesso em: 02/05/2019.

26. Shaner, G.; Finney, R. E. The effect of nitrogen fertilization on the expression of slow-mildewing resistance in knox wheat. Phytopathology, St.Paul v.67, n.8, p.1051-1056, 1977.

27. Wordell Filho, J.A.; Boff, P. Míldio. In: Wordell Filho, J.A.; Rowe, E.; Gonçalves, P.A.; Debarba, J.F.; Boff, P.; Thomazelli, L.F. Manejo Fitossanitário na cultura da cebola. Florianópolis: Epagri, 2006. v.1. cap.2, p.31-43. 